\title{
A REVISION OF THE GENUS DIEROPSIS GAHAN (COLEOPTERA: CLERIDAE: CLERINAE)
}

\author{
By Jonathan R. MAWDSLEY \\ Department of Entomology \\ Museum of Comparative Zoology \\ Harvard University \\ Cambridge, MA 02138
}

\section{INTRODUCTION}

The genus Dieropsis Gahan is certainly one of the most unusual genera of the family Cleridae. Its position within the Cleridae has been discussed by Gahan (1908:95-96), Schenkling (1910:98), Corporaal (1950:244), Crowson (1964:303), and Winkler (1964: $317-329 ; 1982: 519-523)$. Species of the genus Dieropsis display unique characters such as the elongated profemora and protibiae in males of one species and an unusual ocular division which Winkler (1964:317-329; 1982:519-523) has argued call for the establishment of a separate subfamily (Dieropsinae) for this genus. On the other hand, Gahan (1908:95-96), Schenkling (1910:98), Corporaal (1950:244), and Crowson (1964:303) retain the species of this genus within the subfamily Clerinae near the genus Trichodes Herbst. I have been able, through a Hennigian analysis similar to that performed by Ekis (1977:126-134), to show that the sister group of the genus Dieropsis is the genus Trichodes and therefore recognition of a subfamily Dieropsinae would invalidate the previously established subfamily Clerinae by paraphyly.

The number of species in the genus Dieropsis has also been open to debate. Gahan (1908:95-96) described a single sexually dimorphic species, Dieropsis quadriplagiata Gahan, while Winkler (1964:305-329) described the female representatives of Gahan's Dieropsis quadriplagiata as a separate species, Dieropsis femina Winkler. On the basis of my own morphological investigations, I have been able to determine that the majority of specimens identified as Dieropsis femina are actually females of the species Dieropsis quadriplagiata, while those specimens identified as

Manuscript received 19 October 1992. 
Dieropsis femina which are male do not differ in the structure of their genitalia from other males of the species Dieropsis quadriplagiata. I have therefore synonymized Dieropsis femina with Dieropsis quadriplagiata. However, I have found that a second, undescribed species of the genus Dieropsis exists which differs in the structure of its male genitalia from Dieropsis quadriplagiata. This species is described as Dieropsis ralphi New Species below.

\section{List of Collection Abbreviations and Curators}

BMNH - British Museum of Natural History, London, England (D. Kempster)

FMNH - Field Museum of Natural History, Chicago, Illinois, USA (A. F. Newton)

INSB - Institut Royal des Sciences Naturelles de Belgique, Brussels, Belgium (M. Cludts)

JRMA - Jonathan R. Mawdsley Collection (private collection) c/o MCZ, Cambridge, Massachusetts, USA

MRAC - Musee Royal de L'Afrique Centrale, Tervuren, Belgium (H. M. Andre)

MCZC - Museum of Comparative Zoology, Cambridge, Massachusetts, USA (D. G. Furth)

Note: Terminology in descriptions follows that of Ekis (1977). Complete collecting information is only provided for type specimens; for all other specimens, collecting locality only is provided.

\section{Genus Dieropsis Gahan}

Type Species Dieropsis quadriplagiata Gahan (by monotypy)

References: Gahan 1908:95-96; Schenkling 1910:98; Wolcott 1931:330; Corporaal 1950:244; Crowson 1964:303; Winkler 1964:305-329; Winkler 1982:523; Kolibac 1987:105-110;

Kolibac 1989a:26-30; Kolibac 1989b:3-25.

Description:

Head:

As broad as pronotum, black, coarsely punctate. Eyes emarginate in front, divided into two adjacent areas of differently 
sized facets, the facets of the lower part approximately twice as large as the facets of the upper part. Antennae eleven-segmented, terminating in a slightly asymmetrical three-segmented club; club similar in structure to those of species of the genus Trichodes. Labrum distinct and transverse, with a deep sinuate emargination in front. Terminal segment of maxillary palpi cylindrical; terminal segment of labial palpi triangular.

\section{Thorax:}

Pronotum black, coarsely punctured, covered with long dense erect black setae. Subapical depression well developed. Pronotum proper feebly rugulose, more parallel sided than rounded, usually with a longitudinal depression extending medially from the subapical depression to the pronotal collar, bearing laterally a pair of yellow tubercles which are more pronounced in females than in males.

Legs black, heavily sclerotized and coarsely granulate, covered with long dense erect black setae. Metafemora not attaining the apex of the elytra. Tarsi 5-5-5 (not 5-5-4), considerably thickened; segment 1 very small; segment 2 elongate and enlarged, as large as segments 3 and 4 together; segments 3 and 4 of equal size; segment 5 elongate, almost square in cross-section. Segments 2, 3, and 4 bearing small truncate brownish-yellow pulvilli ventrally. Segment 5 with a pair of simple, divergent claws at apex separated by a setulose onychium.

Elytra with coarse, irregular punctures at base, punctures decreasing in size towards apex with apical third of elytra devoid of punctures. Elytra black, except for two large yellowish-orange transverse maculae on each elytron. Epipleural fold concave beneath humeri at base of elytra; otherwise flat. Humeral angle bearing sparse, erect black setae. Elytral maculae with sparse orange-yellow setae; black areas of elytra covered with black pubescence. Apex of elytra feebly and sinuately truncate.

Mesosternum and metasternum black, heavily punctate, covered in thick, black, dense setae, not differing in structure from those of species of the genus Trichodes. Metasternum with a distinct tubercle on either side of discriminal line. 
Abdomen: Ventrally black, heavily punctate, clothed with thick, black, dense setae. Six sterna visible; as in most Clerinae, fifth visible sternite emarginate at apex in males and rounded at apex in females. Sternal depressions reddish-orange in color.

\section{Key to the Species of the Genus Dieropsis Gahan}

1a.) Length from center of frons to elytral apices greater than 20 $\mathrm{mm}$; apex of male tegmen as shown in Figure 3

.Dieropsis quadriplagiata Gahan

b.) Length from center of frons to elytral apices $20 \mathrm{~mm}$ or less; apex of male tegmen as shown in Figure 7

Dieropsis ralphi NEW SPECIES

\section{Dieropsis quadriplagiata Gahan}

Type-Locality: Kondowe, Nyasaland (HOLOTYPE male in BMNH).

References: Gahan 1908:96; Schenkling 1908:481; Schenkling 1910:98; Wolcott 1931:330; Corporaal 1950:244; Winkler 1964:318; Winkler 1982:523.

Synonym: Dieropsis femina Winkler 1964:315-318; Winkler 1982: 523; NEW SYNONYMY (HOLOTYPE male supposedly deposited in MRAC; present location unknown).

Description:

Length: 21.0 to $36.7 \mathrm{~mm}$; mean about $27.1 \mathrm{~mm}$; 202 specimens measured.

Head:

Frons black, deeply and coarsely punctate, covered with long erect black setae. Eyes large, deeply emarginate, divided as described above. Clypeus transverse, black, glabrous. Labrum deeply emarginate, smooth, bearing small scattered punctures and erect black setae. Mandibles large, black, visible in repose; outer fascies coarsely punctate and bearing long erect black setae. Maxillary palpi cylindrical; labial palpi cylindrical except for triangular apical segment. Maxillary and labial palpi black with exception of apices in males which bear a yellow macula. Antennae very similar to those of species of the genus Trichodes. Scape large, triangular in 
cross-section; segments 2-8 subequal in size, more or less cylindrical; segments 9-11 broadly expanded, forming a slightly asymmetrical club. Segments 1-8 with sparse punctures and scattered black setae; segments 9-11 finely, densely punctate, completely covered in short pubescence.

\section{Thorax:}

Pronotum black, coarsely and densely punctate, completely covered with long black setae. Subapical depression strongly arcuate medially. Pronotum proper not broadly expanded, bearing laterally a yellow-orange tubercle; tubercle larger in females than in males. Prebasal depression concave, glabrous; pronotal collar narrow medially but becoming broader apically, coarsely punctate, with long erect black setae.

Legs black, finely and densely punctate, completely covered in short reclinate black setae. Profemora and protibiae of males greatly elongated and slightly arcuate distally, with setae becoming progressively longer towards distal end. Profemora and protibiae of females equal in size to meso- and meta- femora and tibiae. Tarsi as described above; protarsi in males with a lateral fringe of long black setae.

Scutellum transverse, concave, finely and densely punctate, evenly covered with short black setae.

Elytra black with two transverse orange-yellow bands. Basal two-thirds of elytra coarsely and irregularly punctate; apical third of elytra devoid of punctures. Humeral angle with long erect black setae; remainder of elytra clothed in short reclinate pubescence which is yellow above the maculae and black elsewhere.

Mesothoracic wings large, well developed; venation identical to that of Dieropsis ralphi New Species (see below) and similar to that of species of Trichodes such as Trichodes umbellatarum Olivier and Trichodes bibalteatus LeConte.

Mesothorax and metathorax black, densely and coarsely punctate, covered with long erect black setae, not differing in form or structure from those of species of Trichodes. Mesepisternum finely punctate, bearing only short reclinate black setae. 


\section{Abdomen:}

Black, finely and densely punctate, clothed in black reclinate setae. Sternal depressions yellowish-orange in color. Fifth visible ventral abdominal segment deeply emarginate in males, rounded in females. Male external genitalia: tegmen and phallus similar in structure to those of species of Trichodes examined by me; structure of apex of tegmen distinctive (see Figure 3). Female external genitalia: very similar in form to previously described female clerid genitalia.

Illustrations: See Figures 1 and 2 for habitus photographs of a male and female Dieropsis quadriplagiata taken in copula. The dorsal and ventral sides of the apex of the tegmen of Dieropsis quadriplagiata are shown as Figure 3. The head, pronotum, and protibiae of an unusual male specimen (discussed below) are shown in Figure 4.

Discussion of New Synonymy

In the collection of the Institut Royal de Sciences Naturelles de Belgique I discovered a pair of Dieropsis quadriplagiata taken in copula by F. G. Overlaet at Kafakumba, Katanga, Belgian Congo (see Figures 1 and 2). The female is indistinguishable from the "male" holotype of Dieropsis femina as described and illustrated by Winkler (1964:315-318). I thus have no difficulty in synonymizing Dieropsis femina with Dieropsis quadriplagiata on the basis of this evidence.

Further evidence for my conclusion is provided by Winkler himself, when he claims that Dieropsis quadriplagiata (sensu Winkler) is "ninety-nine percent male" while Dieropsis femina is "ninety-eight to ninety-nine percent female" (Winkler 1982:523). In no other species in the family Cleridae are such disproportionate sex ratios known. While a species which was entirely female could reproduce through parthenogenesis, a species which was entirely male would certainly become extinct. It is also extremely unlikely that two species of Cleridae as large as the species of the genus Dieropsis could co-exist in such close ecological association as is indicated by the collection data presented by myself below and by Winkler $(1964: 312,315)$, where individuals of Dieropsis quadriplagiata (sensu Winkler) and Dieropsis fem- 


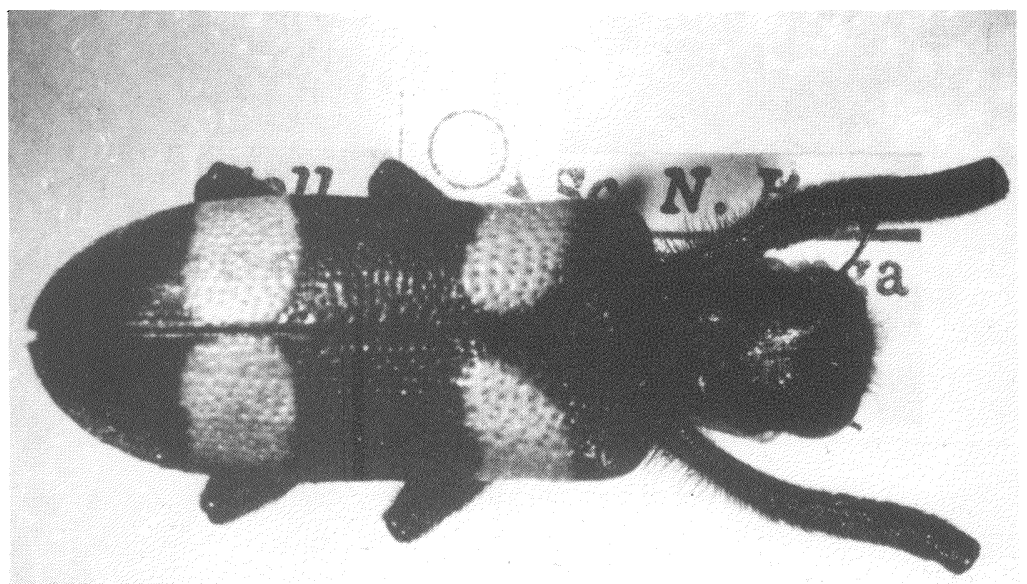

Figure 1: Male Dieropsis quadriplagiata Gahan taken in copula with female shown in Figure 2 by F. G. Overlaet at Kafakumba, Katanga, Belgian Congo (ex INSB). Length of specimen $27.6 \mathrm{~mm}$.

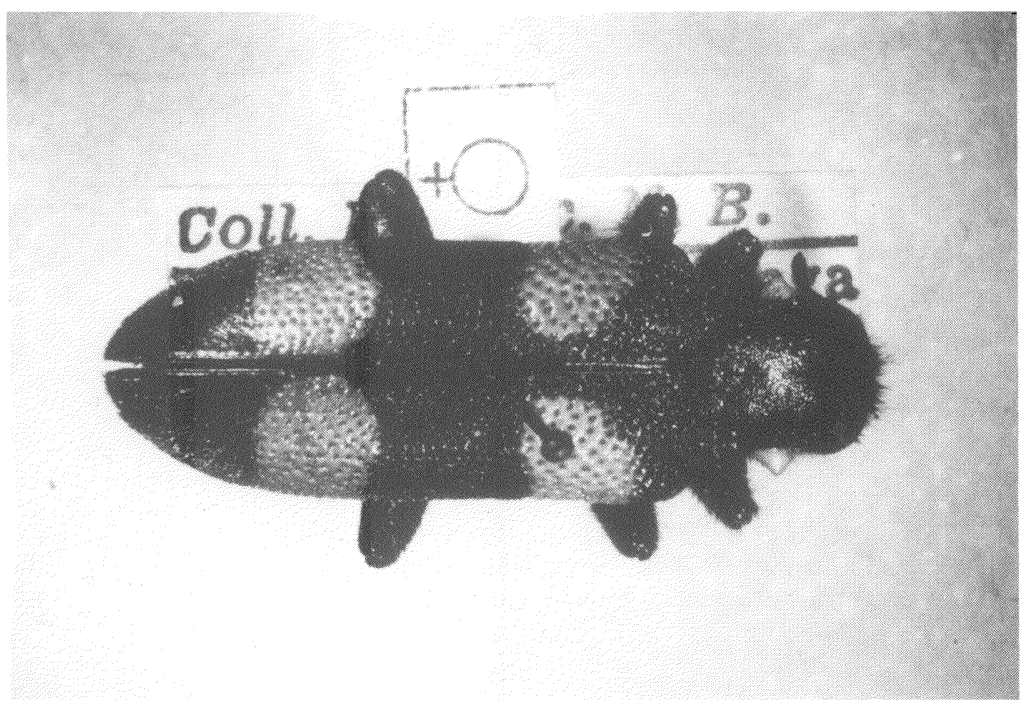

Figure 2: Female Dieropsis quadriplagiata Gahan taken in copula with male shown in Figure 1 (ex INSB). Length of specimen $25.5 \mathrm{~mm}$. 


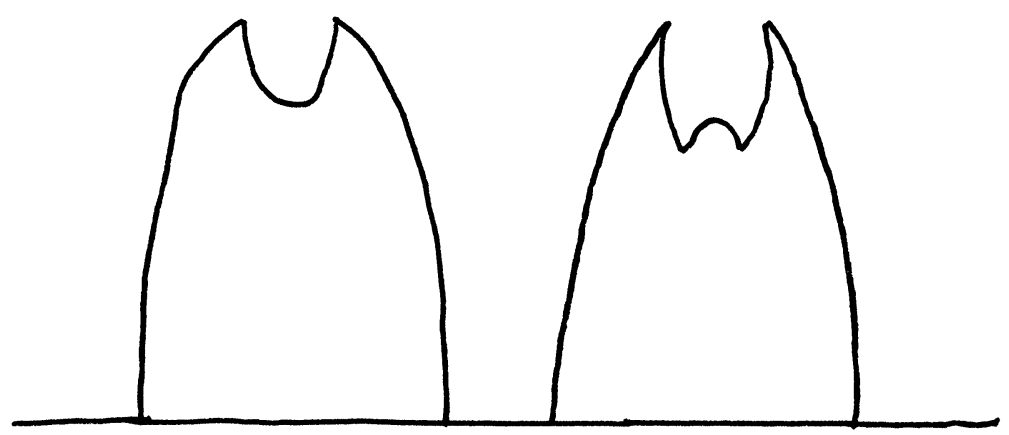

Figure 3: Apex of tegmen of male Dieropsis quadriplagiata Gahan. Left: ventral view; right: dorsal view.

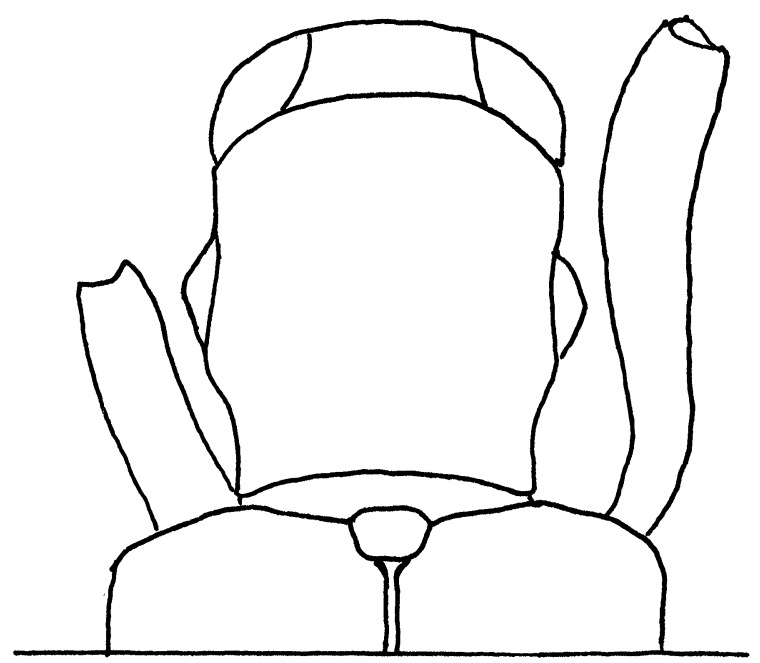

Figure 4: Head, pronotum, protibiae, and humeri of male Dieropsis quadriplagiata Gahan, collected V-1931, Kafakumba, Belgian Congo by G. F. Overlaet (ex MRAC). Length of left protibia $7.4 \mathrm{~mm}$; length of right protibia $10.3 \mathrm{~mm}$. 
ina were consistently collected at the same time in the same locality by the same collector. Furthermore, the characters given by Winkler for separating his two "species" (such as the enlargement of the femora and tibiae and the emarginate versus rounded fifth visible abdominal sternite) are wellknown characters of sexual dimorphism in the family Cleridae.

With regards to the male genitalia dissected by Winkler from a "short-legged" specimen of the genus Dieropsis (see Winkler 1964:306-307), I must note that I have examined a number of male specimens of this species which possessed slightly (and sometimes significantly) shorter profemora and protibiae but which did not differ in any other characters (including genitalic structure) from males with more elongate profemora and protibiae. These males could be readily distinguished from males of Dieropsis ralphi New Species by the differences in the structure of the apex of the tegmen. I have provided a line drawing of a particularly unusual male from Kafakumba in the Belgian Congo (ex MRAC; see Figure 4) in which the left protibia measures $7.4 \mathrm{~mm}$ in length while the right protibia measures $10.3 \mathrm{~mm}$ in length. This specimen clearly illustrates the unreliability of male protibial length for species diagnoses in the genus Dieropsis.

\section{Materials:}

Males:

HOLOTYPE, Kondowe, June 1896, Nyasaland, A. H. Whyte (ex BMNH); Mbweni, Tanganyika Territory (3 specimens ex BMNH, 1 specimen ex MCZC); Livingstonia, Nyasaland (2 specimens ex BMNH); near Malangali, Tanganyika Territory (3 specimens ex BMNH); "German East Africa" (1 specimen ex BMNH); Kafakumba, Katanga, Belgian Congo (71 specimens ex MRAC, 8 specimens ex INSB, 1 specimen ex JRMA); River Luabo, Katanga, Belgian Congo (6 specimens ex MRAC); Kansenia, Katanga, Belgian Congo (1 specimen ex MRAC); Kanzenze, Katanga, Belgian Congo (1 specimen ex MRAC); Kinda, Katanga, Belgian Congo (2 specimens ex MRAC); Bas Lubudi, Katanga, Belgian Congo (3 specimens ex INSB); Muteba, Lulua, Belgian Congo (1 specimen ex MRAC); Kapanga, Lulua, Belgian Congo (2 specimens ex MRAC); Tshala, Lulua, Belgian Congo (3 specimens ex 
MRAC); Sandoa, Lulua, Belgian Congo (12 specimens ex MRAC); River Luvuleji, Lulua, Belgian Congo (1 specimen ex MRAC); Kayombo, Belgian Congo (1 specimen ex MRAC); Katentania, Belgian Congo (1 specimen ex MRAC); Pweto-Kilwa-Kasenga, Belgian Congo (1 specimen ex MRAC); Bururi, Urundi, Belgian Congo (1 specimen ex MRAC); Marungu, Belgian Congo (1 specimen ex INSB); Abercorn, Rhodesia du Nord (2 specimens ex INSB).

\section{Females:}

ALlOTYPE, Fwambo, East Africa (ex BMNH); Mbweni, Tanganyika Territory (2 specimens ex BMNH, 1 specimen ex MCZC); near Malangali, Tanganyika Territory (1 specimen ex BMNH); Kafakumba, Katanga, Belgian Congo (44 specimens ex MRAC, 4 specimens ex INSB, 1 specimen ex JRMA); Muteba, Lulua, Belgian Congo (2 specimens ex MRAC); Sandoa, Lulua, Belgian Congo (8 specimens ex MRAC); Tshala, Lulua, Belgian Congo (1 specimen ex MRAC); Kinda, Katanga, Belgian Congo (2 specimens ex MRAC, 1 specimen ex FMNH); River Luabo, Katanga, Belgian Congo (5 specimens ex MRAC); Kabwe, Lomami, Belgian Congo ( 1 specimen ex MRAC).

\section{Dieropsis ralphi NEW SPECIES}

Description:

Length: 17.3 to $19.5 \mathrm{~mm}$; mean $18.4 \mathrm{~mm} ; 7$ specimens measured. Head:

Large, black, coarsely punctate, covered with black setae, eyes divided as described above (see Figure 5 for illustration), with lower part of eye more prominent than upper part. Labial and maxillary palpi subject to same sexual variation as in Dieropsis quadriplagiata.

Thorax:

Pronotum black, coarsely punctate, covered with black setae. pronotal arch well defined. Pronotum proper with a longitudinal sulcus running from center of subapical depression to pronotal collar. Lateral tubercles exhibit same sexual variation as in Dieropsis quadriplagiata.

Legs black, finely and densely punctate, clothed in reclinate black setae. Profemora and protibiae equal in length to meso- 


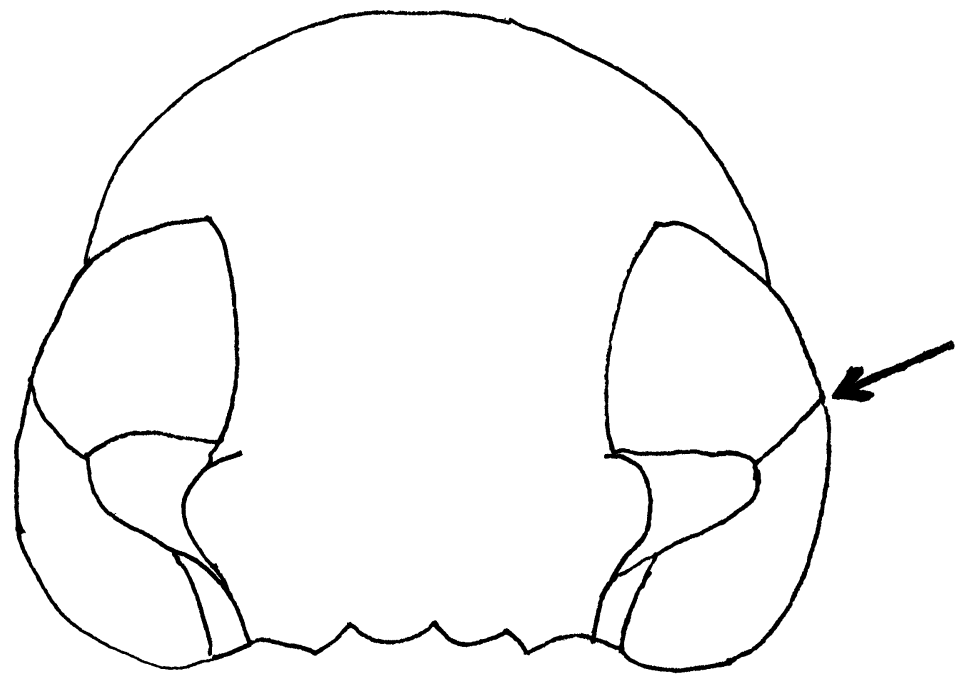

Figure 5: Frons and eyes of Dieropsis ralphi NEW SPECIES. Arrow indicates ocular division.

and meta- femora and tibiae in both sexes. Femora and tibiae with longitudinal carinae. Tarsi as described above; protarsi in males lacking lateral fringe of black setae.

Scutellum finely and densely punctate, slightly concave, covered in short black setae.

Elytra black with two yellowish-orange transverse maculae which both attain the suture. Humeri coarsely, irregularly, and densely punctate; punctures becoming smaller towards apices; apical third of elytra devoid of punctures. Base of elytra with scattered long black setae; maculae with yellow pubescence; remainder of elytra clothed in black pubescence. Metathoracic wings large, well developed (see Figure 6); venation as described for genus by Winkler (1964:309-310) except that R-M vein crosses the "longitudinal stiffener." Anal vein complex (defined to include the four anal veins and corresponding cross-veins) nearly identical to that of species of the genus Trichodes.

Mesosternum and metasternum as described for Dieropsis quadriplagiata. 


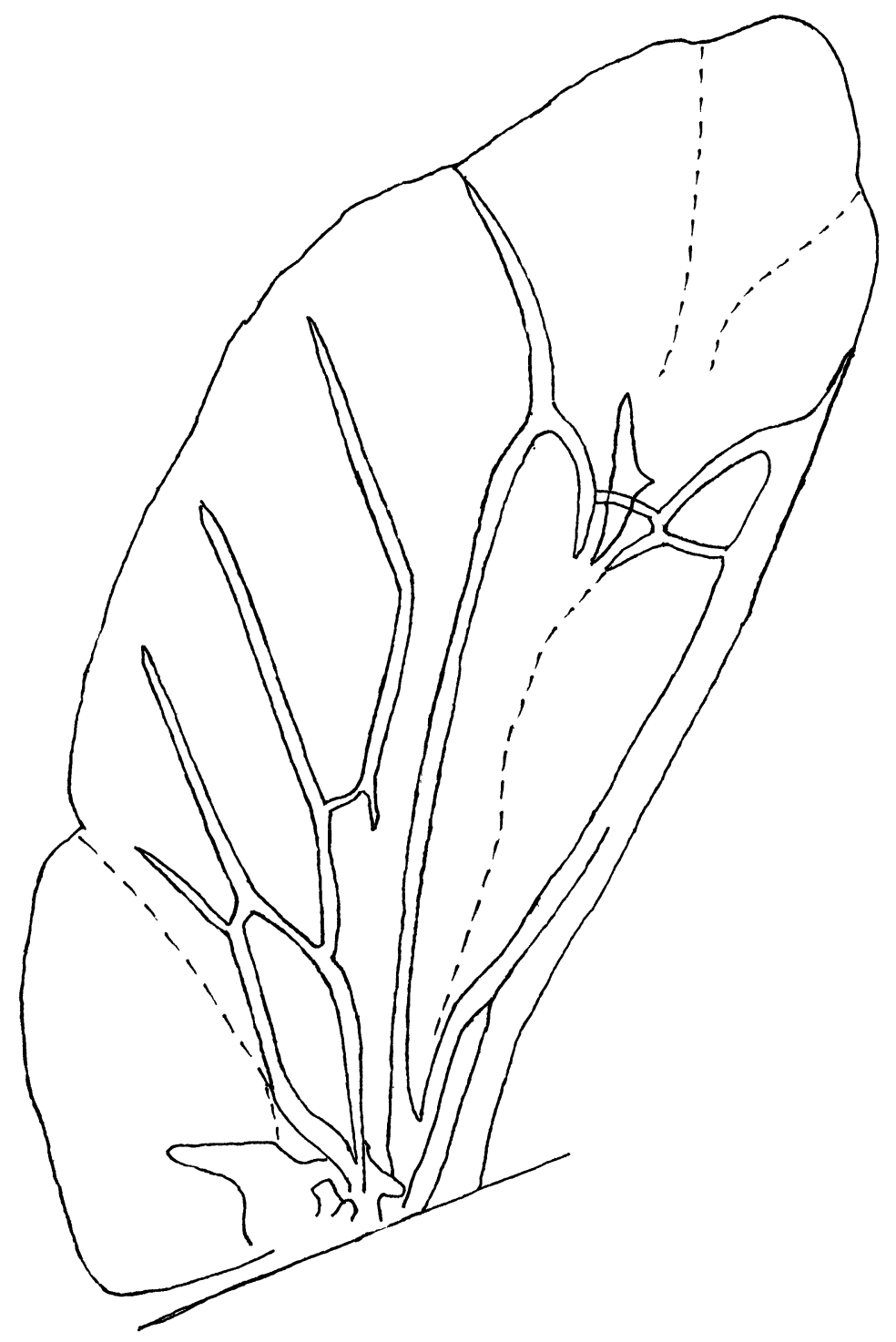

Figure 6: Metathoracic wing of Dieropsis ralphi New Species. Principal folds indicated with dashed lines. 
Abdomen:

Black, coarsely and densely punctured, completely clothed in long black reclinate setae. Sternal depressions reddishorange. Fifth visible sternite emarginate in males, rounded in females. Male external genitalia: Form of apex of tegmen distinctive; see Figure 7. Female external genitalia: Does not differ significantly from that of other described Cleridae.

Illustrations: Line drawings of the frons and eyes, metathoracic wing venation, and dorsal and ventral views of the apex of the tegmen are given as Figures 5, 6, and 7, respectively. Figure 8 is a habitus photograph of the male HOLOTYPE.

Etymology: This species is named in honor of my father, Ralph Dennis Mawdsley, whose devotion to nature has been a constant source of inspiration to me.

Materials:

HOLOTYPE male, Mwengwa, NW Rhodesia, 2740 E 13 S, 27-IV-1913, in hollyhock flower (deposited in BMNH); ALLOTYPE female Kafakumba, Zaire, V-1931, G. F. Overlaet (deposited in MRAC); PARATYPE male, Tshimbalanga, Katanga, Zaire, 27-III-1921, F. G. Overlaet (deposited in MRAC); PARATYPE male, Sandoa, Lulua, Zaire, IV-1931, F. G. Overlaet (deposited in MRAC); PARATYPE female, Muteba, Lulua, Zaire, V-1932, G. F. Overlaet (deposited in MRAC); PARATYPE male, Kafakumba, Zaire, V-1931, G. F. Overlaet (deposited in JRMA); PARATYPE female, Kafakumba, Zaire, IV-1934, F. G. Overlaet (deposited in MCZC).

\section{Biology of Species of the Genus Dieropsis Gahan}

Little is known, aside from speculation by Winkler (1964: 318-324), of the habits of either adults or larvae of the species of the genus Dieropsis. The only biological information accompanying any of the specimens I examined was associated with the holotype of Dieropsis ralphi, which had been collected from a hollyhock flower. It is not surprising that species of the genus Dieropsis frequent flowers, because their closest living relatives (species of the genus Trichodes) are well-known flower visitors.

Numerous species of the genus Trichodes are also mimics of flower-visiting beetles of the family Meloidae. Species of the 


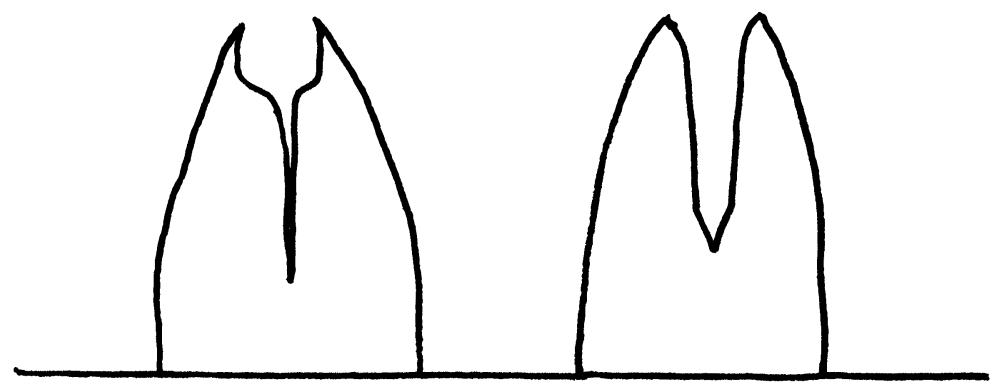

Figure 7: Apex of tegmen of male Dieropsis ralphi New Species. Left: ventral view; right: dorsal view.

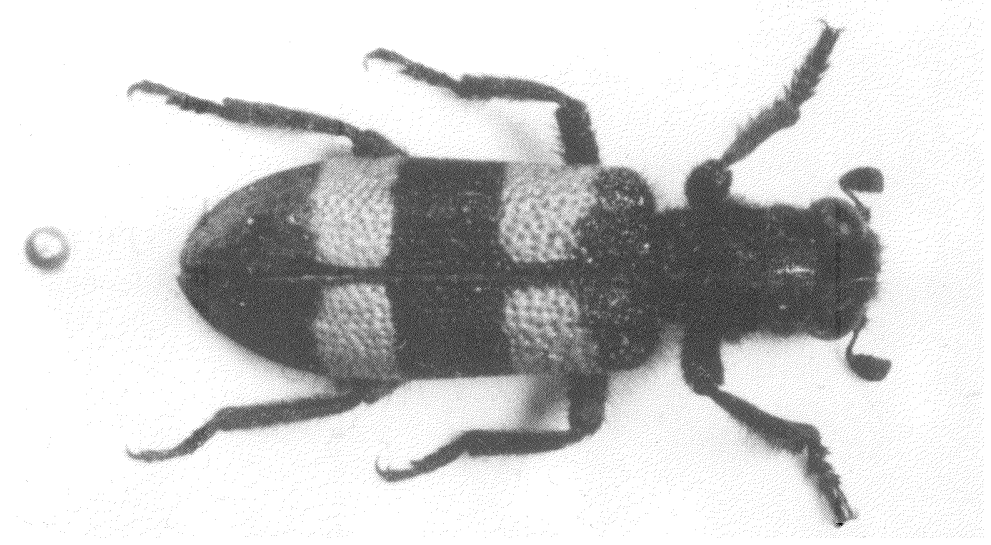

Figure 8: Male HOLOTYPE of Dieropsis ralphi New Species. Collected Mwengwa, NW Rhodesia, 2740 E 13 S, 27-IV-1913, in hollyhock flower. Length of specimen $19.5 \mathrm{~mm}$. Deposited in BMNH.

genus Dieropsis are similar in size and coloration to poisonous meloid beetles of the genus Mylabris Fabricius, found abundantly at the same time and in the same geographical regions. Dieropsis ralphi bears a remarkable resemblance to these meloids, particularly to the common species Mylabris dicincta Bertoloni. Females of Dieropsis quadriplagiata are more similar in appearance to 
these meloids than are males of Dieropsis quadriplagiata. The decreased similarity in the males is due to their elongated profemora and protibiae, characters which may reduce the survival rate of males but which presumably have some importance in sexual selection.

The latter hypothesis is supported by the similarity of the anterior legs of male Dieropsis quadriplagiata to the anterior legs of male Golofa porteri (Hope) (Coleoptera: Scarabaeidae), which are employed in ritualized combat (see Eberhard 1980:166-168). The prothorax of species of the genus Dieropsis is less dorsoventrally compressed than in related genera, indicating an enlargement of those muscles which would be used in manipulating the front legs during such combat. Alternatively, the elongated male profemora and protibiae may be used to grasp the female during copulation.

\section{The Status of the Subfamily Dieropsinae}

Winkler (1964:317-329) erected the subfamily Dieropsinae for the reception of the species in Dieropsis on the basis of a number of unusual characters. In order to ascertain the validity of this action under the current phylogenetic system three questions must be answered: first, would a proposed subfamily Dieropsinae be monophyletic; second, is the sister-taxon of Dieropsis the entire subfamily Clerinae or some smaller group within the Clerinae; and third (which follows logically from the second), would recognition of the subfamily Dieropsinae invalidate any previously existing subfamily-level taxa such as the Clerinae by paraphyly?

I have listed in Tables I and II the various character states which were given by Winkler (1964:317-329) in defining the Dieropsinae as well as the corresponding character states of the genus Trichodes, conventionally assumed to be the sister-taxon of Dieropsis. For outgroup comparison I have used the genus Opilo, which has been conventionally assumed to be the sister-taxon of Trichodes (Foster 1976:7). The format for Tables I and II has been adapted from that used by Carpenter (1987: 415-421).

A number of autapomorphous characters in Dieropsis which are highly convergent in the family Cleridae deserve further comment, since Winkler claims several of these characters are of great importance in establishing the subfamily Dieropsinae. The first of these is the general pronotal structure, which in Dieropsis is similar to 
Table I. Explanation of character states.

\begin{tabular}{ll}
\multicolumn{1}{c}{ Apomorphous } & \multicolumn{1}{c}{ Plesiomorphous } \\
Head & \\
1. Eyes divided & Eyes undivided \\
2. Antennae clubbed & Antennae filiform or serrate \\
Thorax & \\
3. Pronotal tubercles present & Pronotal tubercles absent \\
4. Tarsi thickened & Tarsi more or less filiform \\
5. Tarsal pulvilli small & Tarsal pulvilli large \\
6. First tarsal segment greatly reduced & First tarsal segment small \\
7. Mesothorax and metathorax convex & Mesothorax and metathorax planate \\
ventrally & ventrally \\
8. Mesothorax and metathorax densely & Mesothorax and metathorax lacking \\
pubescent & pubescence \\
9. Metathoracic tubercles present & Metathoracic tubercles absent \\
10. Elytral punctures irregular & Elytra striato-punctate \\
11. Elytral apices devoid of punctures & Elytral apices punctate \\
12. Elytral apices truncate & Elytral apices not truncate \\
13. Vertical stiffener in R-M area of & Vertical stiffener in R-M area of \\
wing present & wing absent \\
14. R-M vein crossing vertical stiffener & R-M vein not crossing vertical \\
stiffener
\end{tabular}

that of species of the Australian genus Eleale (a genus which, in my opinion, is probably closely related to Trichodes). The second convergent character is the pronotal tubercles, which have independently evolved in species of the genera Omadius, Cyclotomocerus, Phyllobaenus, Isohydnocera, Wolcottia, Miohydnocera, Corinthiscus, Pseudichnea, Boschella, Exochonotus, Muisca, Pelonium, and Lasiodera. The thickening of the tarsi with corresponding reduction of the tarsal pulvilli and first tarsal segment has occurred in a number of genera, including Calendyma, Metaxina, and Odontophlogistus. The final convergent character is that of the elytral apices being devoid of punctures. This character has independently evolved in a number of Australian genera, including Trogodendron, 
Table II. Character state matrix for Dieropsis, Trichodes, and Opilo.

\begin{tabular}{rccc}
\multicolumn{2}{c}{$(1=$ apomorphous state present; $0=$ plesiomorphous state present $)$} \\
\hline & Dieropsis & Trichodes & Opilo \\
\hline 1. & 1 & 0 & 0 \\
2. & 1 & 1 & 0 \\
3. & 1 & 0 & 0 \\
4. & 1 & 0 & 0 \\
5. & 1 & 0 & 0 \\
6. & 1 & 1 & 1 \\
7. & 1 & 1 & 0 \\
8. & 1 & 1 & 0 \\
9. & 1 & 0 & 0 \\
10. & 1 & 1 & 0 \\
11. & 1 & 0 & 0 \\
12. & 1 & 1 & 0 \\
13. & 1 & 1 & 0 \\
14. & 0 & 1 & 0 \\
15. & 1 & 0 & 1 \\
16. & 1 & 1 & 0 \\
17. & 1 & 1 & 0 \\
18. & 1 & 1 & 0 \\
\hline
\end{tabular}

Phlogistus, Scrobiger, Neoscrobiger, Tarsostenodes, and Blackburniella, as well as in the Madagascan genus Myrmecomaea. As I stated above, I do not think it wise to base a subfamily-level taxon in the family Cleridae on any of these characters since such a group would almost certainly not be monophyletic (as was the case with Winkler's subfamily Cleropiestinae; see Menier 1981:141).

The first question posed at the beginning of this section is not difficult to answer. From the data presented in Tables I and II it can clearly be seen that the species of Dieropsis share at least six autapomorphous character states $(1,3,4,5,9$, and 11) and are therefore more closely related to each other than to any third species. Hence, Dieropsis is monophyletic and any taxon which contained solely the genus Dieropsis would also be monophyletic.

However, the species of Dieropsis also share at least ten derived character states with the species of Trichodes. Based on outgroup comparison with Opilo, character states 2, 7, 8, 10, 12, 13, 14, 16, 17, and 18 are synapomorphous between Trichodes and Dieropsis. It should be readily apparent from even cursory inspection of Table 
II that the sister group of Dieropsis is, as was first predicted by Gahan (1908:96), Trichodes and not the entire subfamily Clerinae (as would be required for recognition of the Dieropsinae under the current phylogenetic system). From the large number of shared derived character states it seems likely to me that isolation and evolution of Dieropsis have occurred relatively recently.

Having determined that the sister group of Dieropsis is Trichodes, we can now turn to the third question. In my opinion, strict monophyly is critical to a defensible philosophy of classification, particularly in groups such as the Cleridae which have been conventionally regarded as "difficult" groups to study due to the frequency of morphological convergences. Since Trichodes is also related to a group of genera in the subfamily Clerinae including the North American genus Aulicus and the Old World genus Opilo (Foster 1976:7), any classification scheme which recognized a subfamily Dieropsinae would also create a paraphyletic subfamily Clerinae. Therefore, in accordance with strict monophyly, the subfamily Dieropsinae must be synonymized with the previously established subfamily Clerinae.

\section{ACKNOWLEDGEMENTS}

I would like to thank the Ford Foundation and Ralph D. and Alice S. Mawdsley, without whose generous financial support this project would have been impossible. I must also thank Dr. Edward $\mathrm{O}$. Wilson for his guidance and helpful assistance during the course of this project. I would also like to thank the following museum curators for their gracious assistance during my visits to their institutions: P. Hammond and D. Kempster of the British Museum (Natural History); K. Desender and M. Cludts of the Institut Royal des Sciences Naturelles de Belgique; and H. M. Andre of the Musee Royal de L'Afrique Centrale. I would also like to thank A. F. Newton of the Field Museum of Natural History for the loan of a specimen from the collection of A. B. Wolcott. William F. Barr, David G. Furth and Edward O. Wilson are to be thanked for reading and criticizing earlier drafts of this paper. Corinne M. Carter is to be thanked for the generous use of her computer. 


\section{SUMMARY}

The genus Dieropsis Gahan (Coleoptera: Cleridae: Clerinae) is revised, with two species (Dieropsis quadriplagiata Gahan and Dieropsis ralphi NEW SPECIES) recognized. Dieropsis femina Winkler is placed as a synonym of Dieropsis quadriplagiata Gahan, NEW SYNONYMY. Mimicry of species of Meloidae by species of the genus Dieropsis is discussed. Monophyly of the genus Dieropsis is confirmed. The sister taxon of the genus Dieropsis is shown to be the genus Trichodes Herbst, and therefore the subfamily Dieropsinae is placed in synonymy with the previously established subfamily Clerinae to prevent invalidation of the Clerinae by paraphyly.

\section{Literature Cited}

CARPENTER, J. M.

1987. Phylogenetic relationships and classification of the Vespinae (Hymenoptera: Vespidae). Systematic Entomology. 12: 413-431.

CoRporaAl, J. B.

1950. Coleopterorum Catalogus Supplementa, Pars 23, Editio Secunda, Cleridae. The Hague, W. Junk Publishers. 373 pp.

Crowson, R. A.

1964. A Review of the Classification of Cleroidea (Coleoptera), with descriptions of two new genera of Peltidae and of several new larval types. Transactions of the Royal Entomological Society of London. 116: 12: 275-327.

EBERHARD, W. G.

1980. Horned Beetles. Scientific American. 242: 3: 166-182.

EKIS, G.

1977. Classification, Phylogeny, and Zoogeography of the genus Perilypus (Coleoptera: Cleridae). Smithsonian Contributions to Zoology. 227: $1-138$.

FOSTER, D. E.

1976. Revision of North American Trichodes (Herbst) (Coleoptera: Cleridae). Special Publications of the Museum of Texas Tech University. 11: $3-86$.

GaHAN, C. J.

1908. Description of a New Genus and Species of Cleridae. Annals and Magazine of Natural History. 1: 8: 95-96.

KolibaC, J.

1987. Morphological Comparison of Type (or Model) Genera of the Subfamilies of Cleridae. Mitteilungen der Muncher Entomologische Gesellschaft. 77: 103-135.

1989a. Further Observations on Morphology of Some Cleridae I. Acta Scientarium Naturalium Academiae Scientarium Bohemoslovacae Brno. 23: 1: $1-50$. 
1989b. Further Observations on Morphology of Some Cleridae II. Acta Scientarium Naturalium Academiae Scientarium Bohemoslovacae Brno. 23: 2: $1-42$.

MENIER, J. J.

1981. Opinion sur la Sous-famille Cleropiestinae Winkler (Coleoptera: Cleridae), Designations de Lectotypes. Revue Francaise D'Entomologie (Nouvelle Serie). 3: 4: 138-142.

SCHENKLING, $\mathrm{S}$.

1908. Die Cleriden des Deutschen Entomologische National-Museums, Nachtrag II. Deutsche Entomologische Zeitschrift. 1908: 477-487.

1910. Coleopterorum Catalogus, Pars 23, Cleridae. Berlin, W. Junk. 174 pp. WINKLER, J. R.

1964. A Revision of the Genus Dieropsis Gahan 1908, Type of a New Subfamily Dieropsinae N. Subf. (Coleoptera: Cleridae). Acta Universitatis Carolinae (Biologica). 3: 305-329.

1982. Subfamilies and Neutral Terms Proposed for Groups Higher than Subfamily In Cleridae (Coleoptera)-Purposes, Definitions, Identification Key. Acta Universitatis Carolinae (Biologica). 11: 517-531.

WolCOTT, A. B.

1931. A New Species of Cleridae from the Belgian Congo, With Notes on a Few Others. Revue Zoologique et Botanique des Africanes. 20: 4: 328-330. 

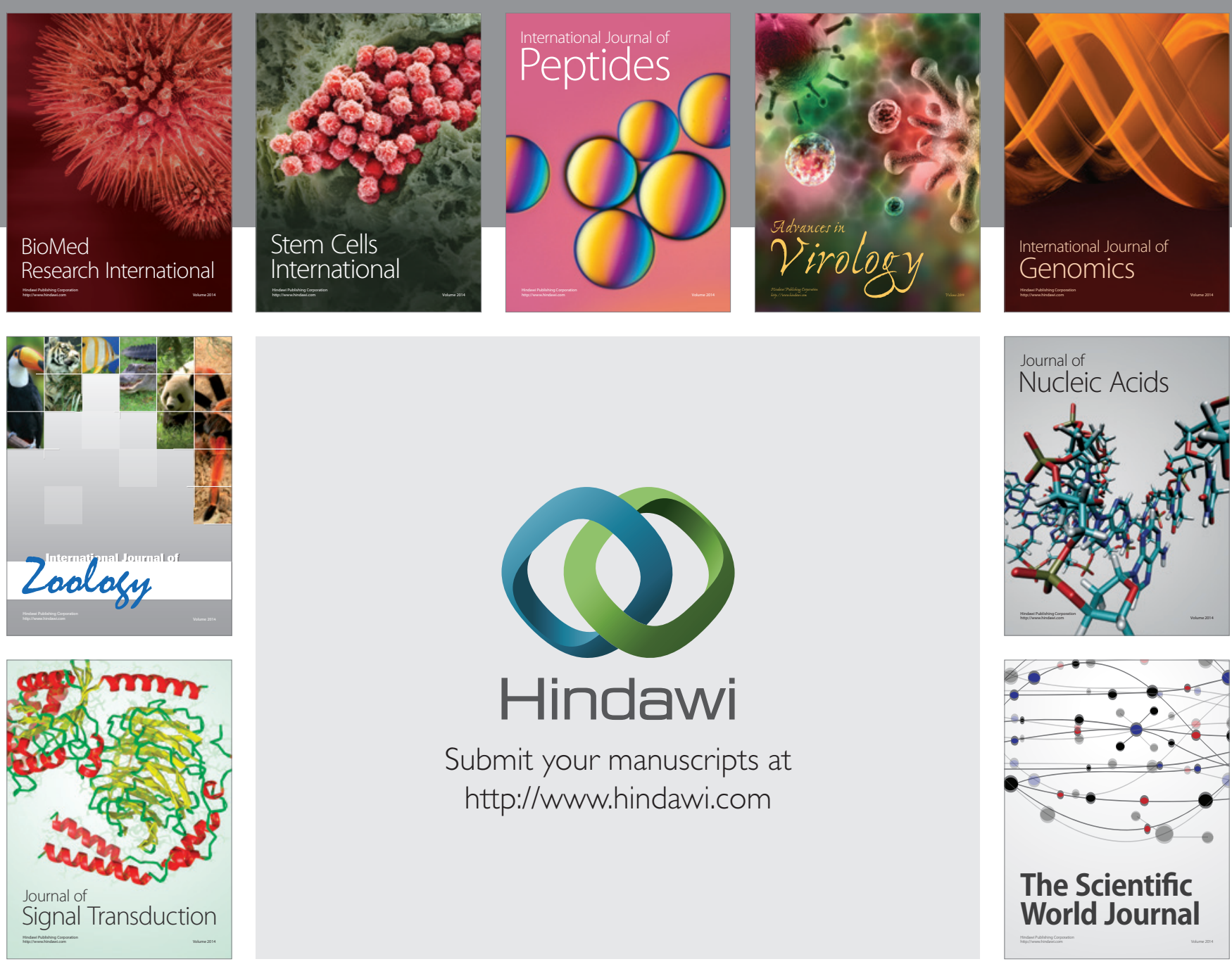

Submit your manuscripts at

http://www.hindawi.com
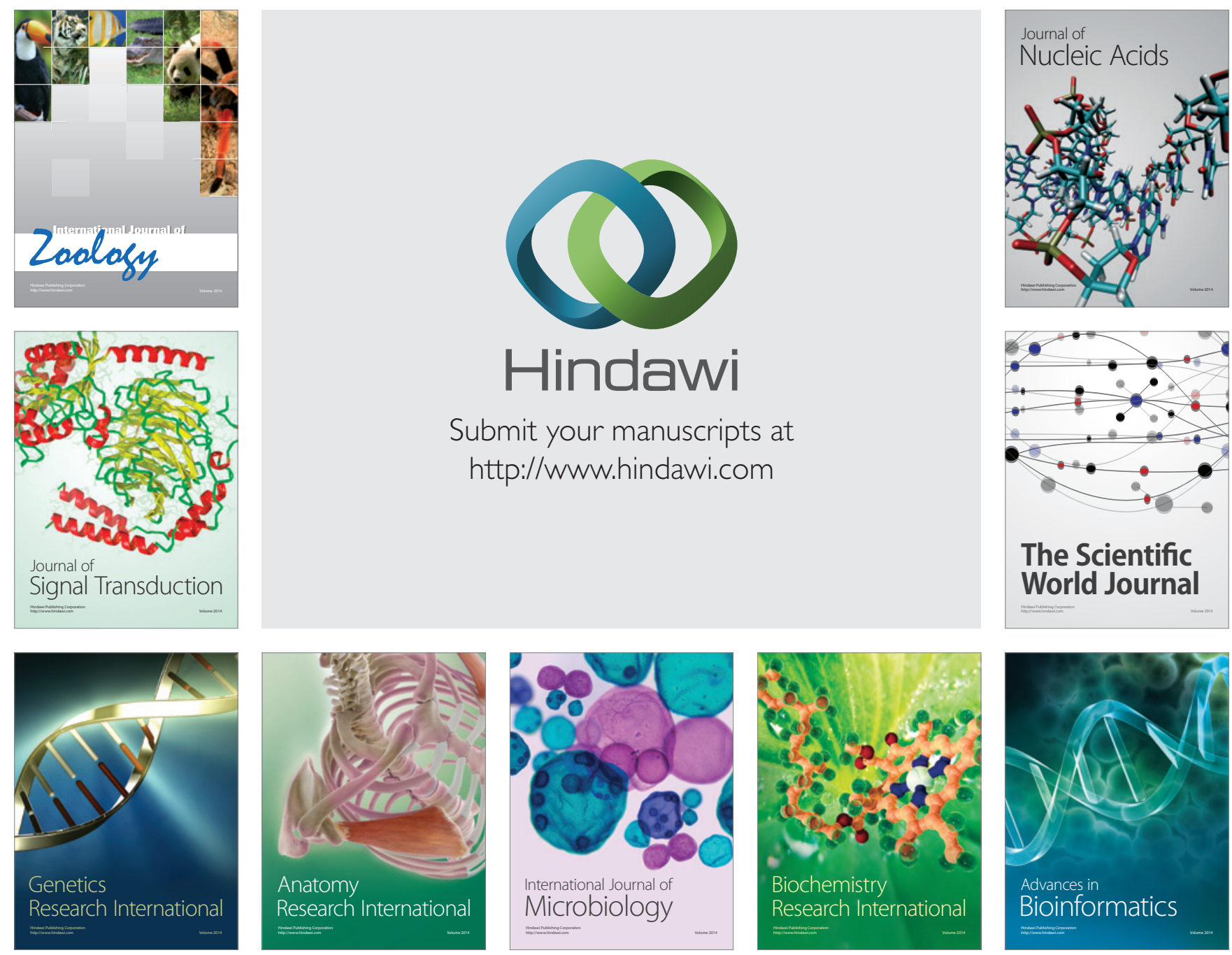

The Scientific World Journal
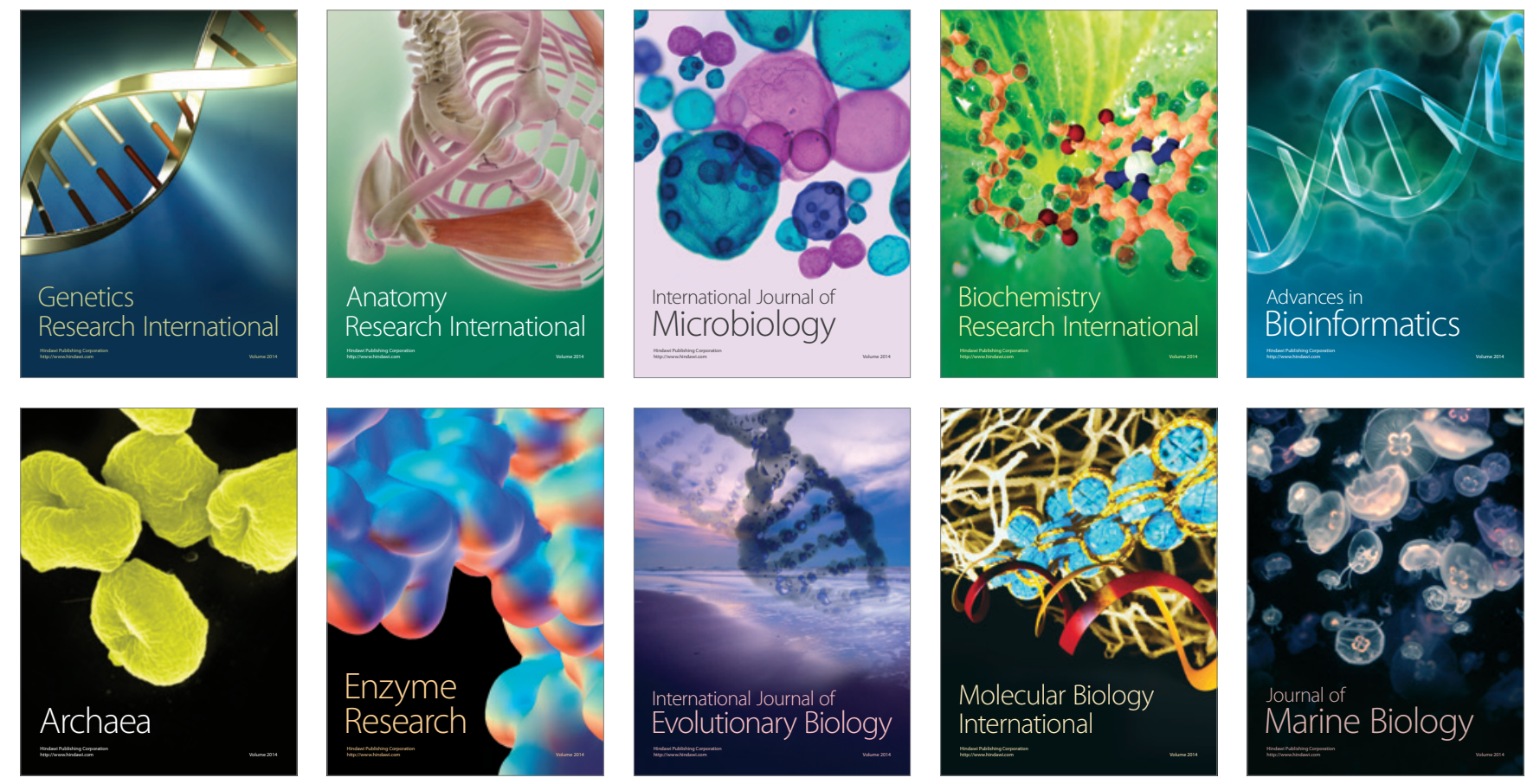